\title{
What does History Matter to Philosophy of Physics?
}

\section{By: Thomas Ryckman}

Naturalized metaphysics remains the default presupposition of much contemporary philosophy of physics. As metaphysics, guided solely by logic and a priori ontology, is supposed to limn the overall structure of reality, so a naturalized metaphysics draws upon the assumed truth of our best physical theories, seeking to answer the "foundational question par excellence": "How could the world possibly be the way this theory says it is?" It is argued that attention to historical detail in the genesis, formulation and interpretation of physical theories provides an ever-relevant prophylactic to the "sentiment of rationality" underlying the naturalistic impulse to read ontology off of physics. 